Boise State University

ScholarWorks

$1-1-2010$

\title{
The Effects of Whole Body Vibration on Bone Mineral Density for a Person with a Spinal Cord Injury: A Case Study
}

Ronald Davis

Texas Woman's University

Charlotte Sanborn

Texas Woman's University

David Nichols

Texas Woman's University

David M. Bazett-Jones

University of Wisconsin - Milwaukee

Eric Dugan

Boise State University 


\title{
The Effects of Whole Body Vibration on Bone Mineral Density for a Person With a Spinal Cord Injury: A Case Study
}

\author{
Ronald Davis, Charlotte Sanborn, and David Nichols \\ Texas Woman's University \\ David M. Bazett-Jones \\ Eric L. Dugan \\ University of Wisconsin, Milwaukee Boise State University
}

\begin{abstract}
Bone mineral density (BMD) loss is a medical concern for individuals with spinal cord injury (SCI). Concerns related to osteoporosis have lead researchers to use various interventions to address BMD loss within this population. Whole body vibration (WBV) has been reported to improve BMD for postmenopausal women and suggested for SCI. The purpose of this case study was to identify the effects of WBV on BMD for an individual with SCI. There were three progressive phases (standing only, partial standing, and combined stand with vibration), each lasting 10 weeks. Using the least significant change calculation, significant positive changes in BMD were reported at the trunk $\left(0.46 \mathrm{~g} / \mathrm{cm}^{2}\right)$ and spine $\left(.093 \mathrm{~g} / \mathrm{cm}^{2}\right)$ for phase 3 only. Increases in leg lean tissue mass and reduction in total body fat were noted in all three phases.
\end{abstract}

The loss of bone mineral density (BMD) is well documented for individuals with spinal cord injury (SCI; Lockette \& Keyes, 1994; Weiss, 2003). Factors reported as affecting bone mineral loss for those with SCI appear to be related to lack of physical activity that produces mechanical loading to the bones and time since injury (Giangregorio \& Blimkie, 2002). Regional patterns of BMD loss for persons with SCI have been reported in the hip, distal femur, and proximal tibia/ fibula areas of the lower body (Kiratli, 2003). The individual's level of injury (those considered paraplegic or tetraplegic), has not been clearly identified in the literature as a contributing factor to BMD loss. Bone mineral density loss is rapid for a person with a SCI during the first 4 years after injury, with some resolve occurring after the fourth year (Jiang, Dai, \& Jiang, 2006; Jones, Legge, \& Goulding, 2002;

\footnotetext{
Ronald Davis, Charlotte Sanborn, and David Nichols are with the Kinesiology Department at Texas Woman's University in Denton. David Bazett-Jones is with the Biomechanics Department at the University of Wisconsin, Milwaukee. Eric Dugan is with the Biomechanics Department at Boise State University in Boise, ID.
} 
Kiratli, 2003; Kiratli, Smith, Nauenberg, Kallfelz, \& Perkash, 2000; Maïmoun, Fattal, Micallef, Peruchon, \& Rabischong, 2006; Poole, Warburton, \& Reeve, 2005). Concern lies with the impact BMD loss can have on quality of life for an individual with a SCI, in particular, increased risk of osteoporosis contributing to fractures.

Jones et al. (2002) reported fracture risk ranging from less than $9 \%$ to as high as $34 \%$ for those with a SCI and to be 1.5-6 times greater for those with a SCI compared with those without a SCI. Fractures for those with a SCI, especially injuries considered to be complete, can occur without notice during daily activities such as transfers in and out of wheelchairs for tasks around the home, work, or community (Giangregorio \& McCartney, 2006; Jones et al.). The incidence of fractures was also the most common associated debilitation for persons with a SCI reported by Lazo et al. (2001). In that study, Lazo et al. measured BMD in 41 individuals with a SCI and the results indicated 34\% of all participants reported having fractures in the lower extremities. Therefore, reducing the risk of fractures for persons with a SCI could positively impact adult daily living skills and improve quality of life.

Rehabilitation treatments such as passive standing, aided walking (Giangregorio, et al. 2006), physical exercise, functional electrical stimulation, or low-intensity ultrasound have been used to address BMC loss. Additionally, pharmacological treatments such as the use of calcitonin or bisphosphonates to promote bone resorption have been cited (Maïmoun et al., 2006). Functional electrical stimulation interfaced with a Parastep training program or seated cycle ergometry for the purpose of improving BMD for those with a SCI, has also been reported as having no significant impact on BMD (BeDell, Scremin, Perell, \& Kunkel, 1996; Chen et al., 2005; Leeds, Klose, Ganz, Serafini, \& Green, 1990; Needham-Shropshire et al., 1997). Both rehabilitative and pharmacological treatments have been reported as being disappointing with regard to improving BMD for those with disabilities (Maïmoun et al., 2006).

In two separate studies, Maïmoun et al. (2006), and Abercromby et al. (2007) suggested the challenge was to apply sufficient levels of stimulus (electrical or mechanical) without increasing the risk of fractures for individuals with reduced BMD. Maïmoun and colleagues have also suggested the use of some combination of verticalization (standing) and vibration frames (platforms) to address BMD loss. Abercromby and associates suggested that placing a mechanical load on bone material can stimulate improvement in BMD.

Assistive standing has been identified as an intervention to improve quality of life and other health concerns of persons with SCI. Prolonged (i.e., one year) assisted standing had positive effects on 126 individuals with SCI on the health related areas of circulation, skin integrity, reflex activity, bladder function, and fatigue (Eng et al., 2001). Improvements such as reduction of bed sores, fewer bladder infections, and increased leg range of motion have also been documented (Walter et al., 1999). The use of assistive standing devices has been suggested to address secondary medical complications related to a SCI, such as a reduction of muscle mass and increase in body fat (Jacobs \& Beekhuizen, 2005; Kocina, 1997); however, the literature does not report assistive standing as an intervention to improve BMD for those with lower body impairments such as a SCI (Eng et al., 2001).

Whole body vibration (WBV) has been used to address improvements in BMD and lean tissue mass for individuals without SCI, such as postmenopausal women or college athletes (Bogaerts et al., 2007; Delecluse, Roelants, \& Verschueren, 2003; 
Garatachea et al., 2007; Jordan, Norris, Smith, \& Herzog, 2005; Moran, McNamara, \& Luo, 2007; Roelants, Delecluse, Goris, \& Verschueren, 2004; Verschueren et al., 2004). Whole body vibration is a neuromuscular training method that requires the participant to stand on a platform that generates vertical sinusoidoal vibration at a selected frequency and amplitude (Delecluse et al., 2003).

The frequency of vibration is recorded in hertz $(\mathrm{Hz})$ or the number of vertical displacements per second ranging from 15 to $60 \mathrm{~Hz}$ and displacements (amplitudes) are reported as ranging from $\sim 1-11 \mathrm{~mm}$ (Dolny \& Reyes, 2008). According to Dolny and Reyes, "the acceleration on the body while on the vibration platform can be estimated from the following equation: $\mathrm{a}=\mathrm{A} *(2 \pi f)^{2}$ using $a$ to represent the acceleration of earth's gravity $(g), A$ as the amplitude of displacement, and $f$ is the frequency of vibration in Hz" (p. 152). The duration (time) of vibration is recorded in seconds per vibration bout. As a person stands on the platform, the stimulus impacts the muscular system indirectly through the legs and attempts to damper these vibrations leading to increases in soft tissue stiffness (Dolny \& Reyes). Improvement in BMD has been hypothesized as resulting from high-frequency loading of the skeleton or mechanical loading to the bone (Verschueren et al., 2004). Individuals with a SCI can engage with a vibration platform while seated in their wheelchair using foot placement on the platform (personal communication, J. Ryaby, Spring, 2005).

Whole body vibration has been suggested to have potential benefits for BMD in postmenopausal women (Flieger, Karachalios, Khaldi, Raptou, \& Lyritis, 1998; Rubin et al., 2004). These studies investigated BMD loss in postmenopausal women using low-magnitude vibration. Rubin et al. reported on women $(N=70)$ with a range of 3-8 years postmenopause who stood on a small vibration platform two times per day (10 min each), 7 days per week for 1 year. Results of the study indicated that brief periods of low-magnitude vibration $(0.2 g @ 30 \mathrm{~Hz})$ did improve BMD at the spine and femur sites. Verschueren et al. (2004) reported the effects of WBV over 6 months on the hip BMD, muscle strength, and postural control of postmenopausal women by randomly assigning the women to either of three groups (resistance training, WBV, or control). The WBV and resistance training group trained three times per week for 24 weeks, in a progressive fashion. Whole body vibration was set at $35-40 \mathrm{~Hz}$ and 2-5 g's and results indicated significant changes in BMD for the WBV group at the hip with no changes for the resistance training or control group at this site.

A study by Ward et al. (2004) reported the effects of low-magnitude vibration in children with disabling conditions (specific disability categories not identified). Twenty pre- or postpubertal children with disabilities were randomly assigned to stand on an active $(0.3 g, 90 \mathrm{~Hz})$ or placebo (no activity) device for $10 \mathrm{~min} /$ day, 5 days/week for 6 months. Results indicated over a $6 \%$ improvement in BMD at the proximal tibia for those children who stood on the active device compared with those who stood on the placebo. The authors suggest low-magnitude, high-frequency vibration could be beneficial for trabecual bone development.

Whole body vibration has been reported (Bogaerts et al., 2007) to enhance lean body mass in older men. In a study similar to Delecluse et al. (2003), Bogaerts and colleagues (2007) compared control, fitness, and WBV interventions and their effect on muscle mass; results were reported that similar enhancements occurred in both the fitness and WBV groups. Roelants et al. (2004) also described increases 
in fat free mass following 6 months of a progressive, WBV intervention. Potential lean tissue mass gains could be similar to those reported for individuals without a SCI (Delecluse et al., 2003).

Loss of BMD for persons with a SCI has been associated with quality of life concerns (i.e., disease and fractures). Interventions to address BMD loss for persons with a SCI have included rehabilitative and pharmacological treatments, which have produced inconsistent results. In an attempt to negate BMD loss, the use of WBV has been reported with postmenopausal women and children with disabilities; results were promising (Rubin et al., 2004; Verschueren et al., 2004; Ward et al., 2004). The use of standing devices to address BMD for persons with a SCI has not yielded significant improvements (Eng et al., 2001). Whole body vibration has been suggested as an effective intervention to address loss of BMD for those with lower body impairments (i.e., SCI) but has not been reported in the literature (Maïmoun et al., 2006). Therefore, using a case study design as defined by Portney and Watkins (2009), the primary purpose was to identify what effect WBV had on changes in BMD for a person with a SCI, with a secondary purpose being to investigate changes in lean tissue mass and body fat.

\section{Method}

\section{Participant and Data Collection Procedure}

A single-person case study was used to investigate the effects of WBV because of the unknown effects of this intervention in a SCI population. A 27-year old female participant, 4 years post injury, with an incomplete SCI at thoracic 10 (T 10) consented to participate in the study. There were three phases to the study, each lasting 10 weeks, with 7-week nonactivity intercessions between each phase for a total of 51 weeks (Semerjian, Montague, Dominguez, Davidian, \& de Leon, 2005; Walter et al., 1999). The intervention phases were based on previous research and semester scheduling.

Height and weight were measured before the start of each 10-week phase. Height was measured while she was supine on the Dual Energy X-ray Absoptiometry (DXA) scanning bed, and weight was measured using a digital freight scale. Pre/ post total body scans for each phase using DXA, which measures BMD $\left(\mathrm{g} / \mathrm{cm}^{2}\right)$, lean tissue mass (gm), and body fat (\%), were made. Assisted transfers from the participant's wheelchair to the bed of the DXA were performed under supervision of an athletic trainer.

Whole body vibration was provided by a Power Plate Next Generation vibration platform (Power Plate North America, Chicago, IL) and assisted standing was accomplished using an Easy Stander 5000 (Altimate Medical, Morton, MN). At the beginning of each trial for all three phases, the participant was assisted to a padded treatment table and allowed to lie in a prone position to facilitate hip extension and serve as a warm-up routine. Warm-up took approximately 5-8 min and when ready, the participant was assisted to the standing frame.

Correct positioning in the standing frame was checked by an athletic trainer, who was provided a positioning inservice before and during all sessions.

The intervention protocol for this study was intended to be progressive in regards to WBV frequency, magnitude (or intensity), and duration, since this has 
previously been show to be effective in a healthy population (Delecluse et al., 2003; Verschueren et al., 2004). The protocol transitioned from standing without vibration (phase 1), partial standing or feet on platform with WBV (phase 2), concluding with standing and WBV combined (phase 3). See Figure 1 for body positions of each phase and Table 1 for a summary of the intervention protocol for phases 2 and 3. Vibration magnitudes $(g)$ were measured in a previous study (Bazett-Jones, Finch, \& Dugan, 2008) on the same vibration platform used for both phases of the current study.

Phase 1-Standing Only. The first phase used only a standing intervention. Standing occurred 3 times per week for 40 min per visit across 10 weeks (Eng et al., 2001). The participant used a standing frame during this phase. Movement from sitting to standing and standing to sitting was accomplished with a slow and controlled pace to address any concerns related to postural hypotension (Rimmer, 1994).

Phase 2-Partial Standing and WBV. The second phase used two interventions of passive standing with nonsimultaneous vibration (feet only on platform). The standing and separate WBV session occurred 3 times per week for 10 weeks and was divided into two 20 min segments for each intervention. The standing protocol described earlier in phase 1 was repeated for the first $20 \mathrm{~min}$. The second $20 \mathrm{~min}$ session required the participant to move out of the standing device and place her feet on the vibration platform while seated back in her wheelchair (personal communication with J. Ryaby, spring, 2005; see Figure 1). With her feet on the platform, she was asked to perform three isometric exercises, two requiring use of nylon straps attached to the platform: (a) seated dip (no straps used), (b) bicep curl, and (c) upright row. During the seated dip exercise, the participant was asked to raise her buttocks from the seat of the wheelchair, using the arms of the wheelchair, until her elbows where extended. The purpose of the seated dip exercise was to increase the weight-bearing load to the lower extremity, which was hypothesized to increase the effectiveness of the vibration compared with only placing the feet on the vibration platform. During the bicep curl and upright row exercises, the participant received vibration stimulation both to her lower extremity (feet on platform) and to the upper extremity via the nylon straps. She was asked to hold each exercise for the duration of the vibration set with rest periods between each vibration set that were equal in time to a vibration set.

Phase 3-Combined Standing and WBV. This phase combined standing and vibration in a simultaneous intervention and occurred 3 times per week for 7 min of vibration per session. A prototype ramped wooden deck was designed to be placed over the vibration platform and allow foot access to the surface of the platform through a hole in the deck. The participant was placed in the standing frame and rolled up the ramp in a seated position to the top of the deck; once secured on the deck she was raised to standing. Once in a standing position, the participant's feet were directly placed onto the vibration platform through the hole in the deck (see Figure 1). 


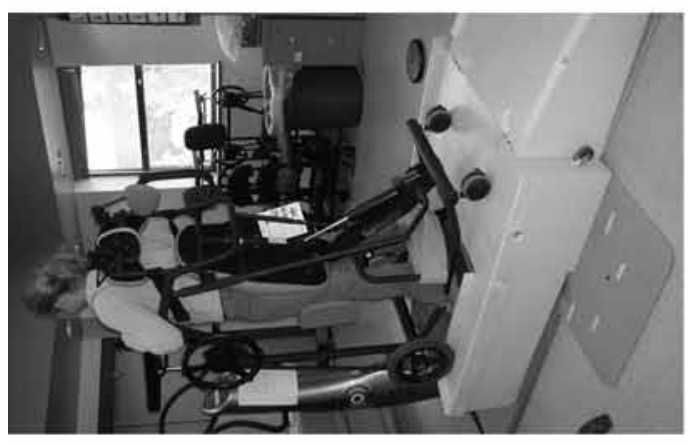

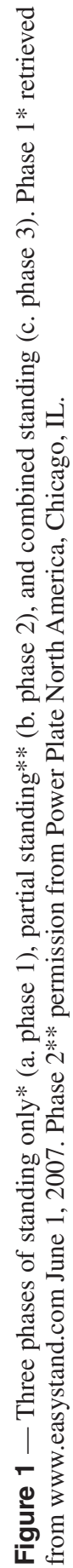

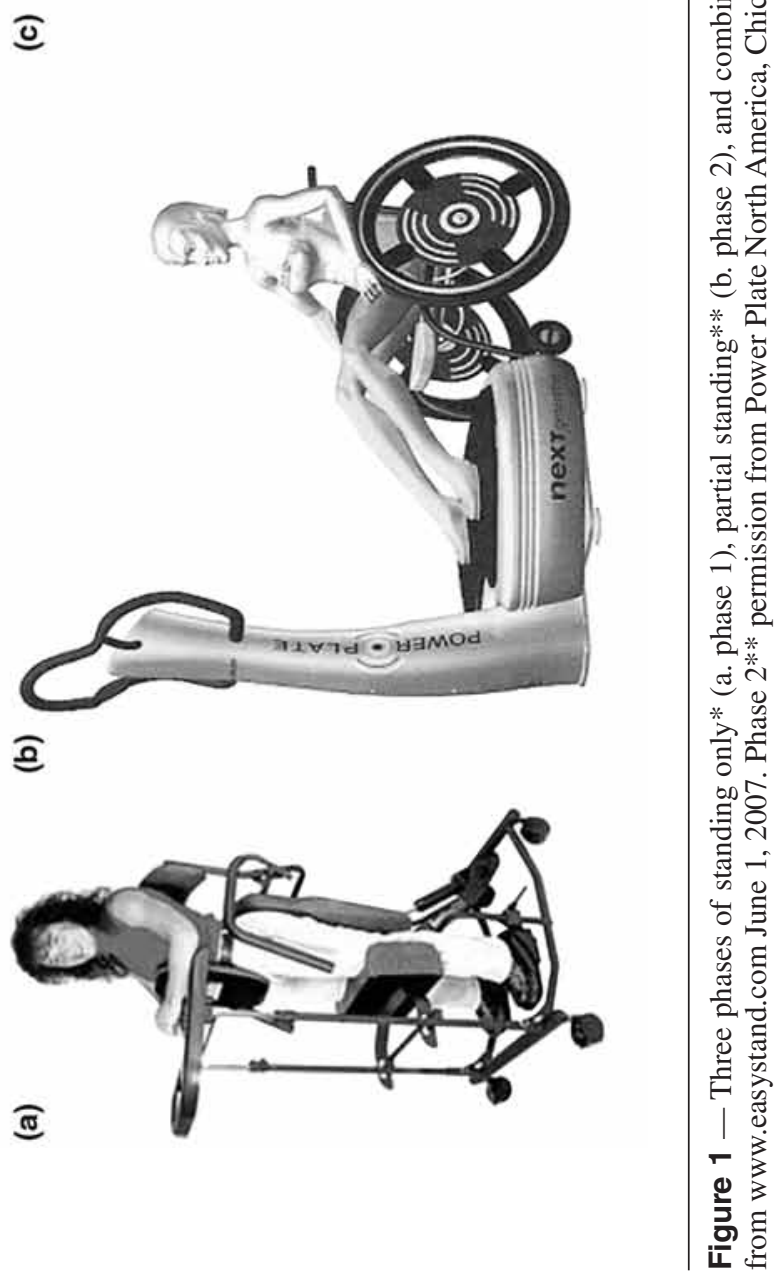


Table 1 Ranges, Means (SD) of Whole Body Vibration Frequency, Magnitude, Duration, Sets, and Visits for Phases 2 and 3

\begin{tabular}{lccccc}
\hline & $\begin{array}{c}\text { Frequency } \\
(\mathbf{H z})\end{array}$ & $\begin{array}{c}\text { Magnitude } \\
(\mathbf{g})\end{array}$ & $\begin{array}{c}\text { Duration } \\
(\mathbf{s})^{\star \star}\end{array}$ & Sets & Visits/wk \\
\hline Phase 2* & & & & & \\
Week 1-10 & $30-50$ & $2.16-5.83$ & $49.5(7.25)$ & $2.5(0.53)$ & $2.9(0.74)$ \\
$\begin{array}{l}\text { Phase 3 } \\
\text { Week 1-10 }\end{array}$ & $30-50$ & $2.16-5.83$ & $72.0(23.24)$ & $6.1(1.60)$ & $2.9(0.57)$ \\
\hline
\end{tabular}

*Note: daily sets included 3 exercises of seated dip, bicep curls, and upright row.

*** Means and $S D$

\section{Statistical Analysis}

Descriptive statistics (means, standard error, percentages) were used to report the data for each session. Data were reported according to body segments from the DXA total body scan (trunk, pelvis, spine and legs). Percent of change for BMD, lean tissue mass, and body fat changes were calculated by subtracting the post measures from the pre measures to determine the difference from pre to post, then dividing the difference by the pre measure to determine the percent change.

To determine if changes in BMD should be considered significant, a precision error (PE) quotient and least significant change (LSC) measure were used as recommended by the International Society for Clinical Densitometry (www.iscd.org retrieved July 2008). The precision error reported by the university laboratory was used for comparisons. The intent of the precision error measure is to determine the technologist's precision on a particular machine without introducing uncontrolled variables (ISCD) and is reported as Root Mean Square Standard Deviation (RMS $S D)$. Least significant change is a value calculated by multiplying the precision error by 2.77 for a $95 \%$ confidence level. Bone mineral density change equal to or exceeding the LSC would be considered significant. The LSC calculation was not applied to changes in lean tissue mass or body fat.

\section{Results}

The participant was a 27-year-old female with an incomplete SCI at T10, with a height of 66" (168cm) weighing $127 \mathrm{lb}(58 \mathrm{Kg})$. Precision error for BMD $\left(\mathrm{g} / \mathrm{cm}^{2}\right)$ at the trunk, pelvis, and spine were calculated at $0.014,0.02$, and 0.03 respectively. Changes in BMD that exceed LSC can be attributed to changes in BMD at a 0.95 confidence level. All BMD, lean tissue mass, and body fat results can be seen in Table 2.

The results from phase 1 supported the literature in that no positive changes of BMD were identified from standing only (see Table 2). Bone mineral density loss was identified for each of three sites (trunk, pelvis, and spine) with the greatest loss appearing in the pelvis as measured by BMD. Assisted standing appeared to increase lean tissue mass in the legs $(44 \%)$ and for the entire body $(4.34 \%)$ while reducing body fat in the same regions (5.29\% and 5.5\%, respectively). 


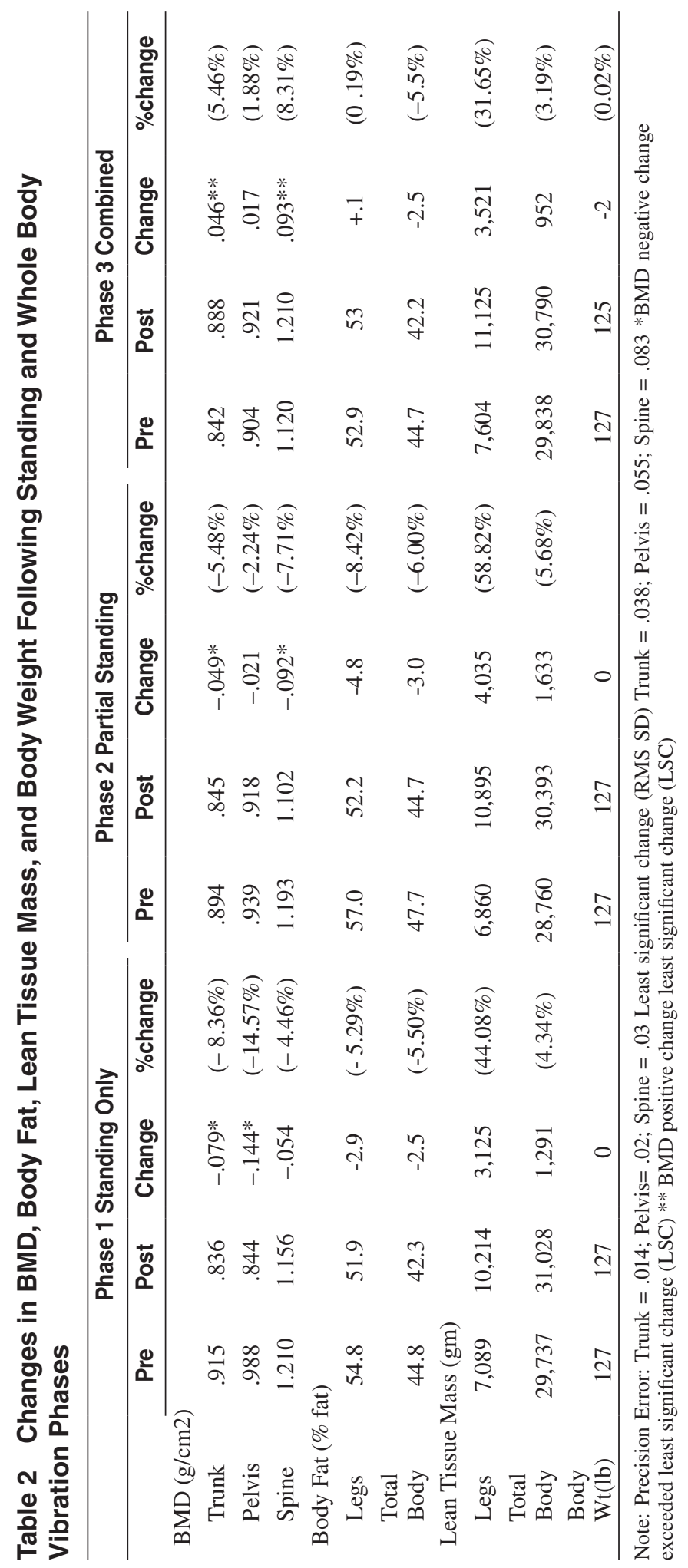


Phase 2 results were similar to those recorded in phase 1 . Bone mineral density loss was reported in two of the three body sites (trunk, pelvis); however, the percent loss at all three sites was less than phase 1 . Bone mass changes in the spine can be affected by the loading of lower vertebral segments while in a seated position (Kiratli, 2003). Results of regional lean tissue mass increase and body fat reduction were similar to phase 1 .

Phase 3, which used the combination of standing with simultaneous WBV, produced the only significant positive changes in BMD for the trunk $\left(0.046 \mathrm{~g} / \mathrm{cm}^{2}\right)$ and spine $\left(0.093 \mathrm{~g} / \mathrm{cm}^{2}\right)$. The pattern of increased lean tissue mass and reduction of body fat was consistent with the previous two phases. A slight weight loss of 2 lbs was noted during this phase.

\section{Discussion}

This case study was conducted to determine what effect WBV had on changes in BMD for a person with a SCI. The interventions of assisted standing alone (phase 1) and partial standing with feet on WBV platform (phase 2) did not produce positive changes in BMD. Perhaps the most important finding resulted from the effects of the intervention in phase 3 (standing combined with simultaneous WBV). This was the only phase that recorded significant positive changes in BMD at two sites (trunk and spine). During this phase, the standing device was placed over the vibration platform allowing the participant's feet to directly rest on the surface of the vibration platform. By positioning the participant on the platform, a greater load was created, which might have enhanced the vibration throughout the entire body. Rubin et al. (2004) and Verschueren et al. (2004) have reported BMD improvement in postmenopausal women who stood on both a low-magnitude (Rubin et al., 2004) or high-magnitude (Verschueren et al., 2004) vibration platform. Our results seem to support these previous studies in an individual with SCI, possibly due to the increased load caused by the combination of weight bearing and WBV.

In addressing the secondary purpose of this study, all three phases positively impacted regional lean tissue mass (i.e., legs) and body fat, which is supported by the standing literature (Eng et al., 2001; Jacobs \& Beekhuizen, 2005; Kocina, 1997) and the WBV literature (Bogaerts et al., 2007; Roelants et al., 2004). Our findings also seem to support the published literature with increases in lean body mass and decreases in body fat across all phases. In phase 2, which used a separate 20-min standing session followed by a separate partial standing WBV (feet on platform), the greatest changes of lean tissue mass and reduction of fat occurred in the legs when compared with phases 1 and 3 . Whole body vibration has been reported to trigger involuntary muscle contractions and contribute to strength gains in untrained individuals without a SCI (Bogaerts et al., 2007; Delecluse et al., 2003). The individual within the current study had a SCI considered incomplete (partial motor and/ or sensory function), which could have contributed to this improvement. Delecluse and associates (2003) further suggested that using WBV to promote muscle mass improvements in a therapeutic context may be attractive to subpopulations such as elderly or those with disabilities. Whole body vibration generates a mechanical stimulus that is transmitted throughout the entire body and reaches sensory receptors (i.e., muscle spindles) and when activated, the muscle spindles excite the alpha motoneurons to initiate muscle contraction (Garatachea et al., 2007). 


\section{Implications}

While it is not appropriate to generalize to all persons with SCI based on the results of this case study, the results support earlier literature with regard to improvement in BMD (Eng et al., 2001; Rubin et al., 2004; Verschueren et al., 2004) and lean body mass (Bogaerts et al., 2007; Eng et al., 2001; Roelants et al., 2004). It would appear likely that improvement in one's lean tissue mass, reduction in body fat, and increase in BMD would be the type of results hoped for to help individuals with a SCI. The results of this study might suggest direction for future studies.

\section{Limitations}

This case study is not reported without recognizing limitations. The single greatest limitation of this investigation is that it is a case study and should not be generalized to other individuals with SCI. The protocols used in this study may not have been the most effective for this type of intervention. The researchers chose to follow the logic of progressive resistance training applied to $\mathrm{WBV}$, similar to the protocols used by others (Bogaerts et al., 2007; Roelants et al., 2004; Verschueren et al., 2004). The use of specially built ramp to access the vibration platform could affect replication of the study. Lastly, the schedule of intervention was established to meet the demands of the participant (college student), which varied from fall to spring semesters but averaged 3 days per week across the study. The participant was not currently exercising and had previous experience with transfer skills. These factors, related to the individual participant, might have affected the outcomes of this case study.

\section{Future Recommendations}

Mechanical stimulation of muscle spindles using WBV should be further investigated, especially with those individuals who have an incomplete SCI. Further investigation should consider a closer look at the dose of intervention, i.e., intensity, duration, and frequency of WBV. To date not enough information is known regarding dosage of WBV for these three variables. Future studies should consider research designs that would identify the effects of manipulating duration and frequency while holding intensity ( $\mathrm{Hz}$ and amplitude) constant. Manipulation of sets, repetitions, and resistance is widely understood for exercise training using free weights or machines, but not so with the use of WBV. Future research should also be considered to better address the manipulation WBV dosage.

Additional research needs to occur that addresses larger sample size, type of injuries (i.e., paraplegic, tetraplegic, complete, incomplete), date of injury, activity lifestyle, and dosage of vibration. More specific DXA scans need to be used (i.e., hip, distal femur/proximal tibia-fibula); however, such scans require specialized training by DXA technicians. Affective changes (Eng et al., 2001) should also be documented and measured simultaneously during vibration intervention. This suggestion is based on anecdotal comments by the participant (e.g., "my appetite has improved," "I am sleeping better at night," "I am experiencing fewer spasms"). Improving quality of life for persons with a SCI should be the focus of future research. The use of WBV as an intervention to address BMD loss for this population needs further study. 


\section{References}

Abercromby, A.F.J., Amonette, W.E., Layne, C.S., McFarlin, B.K., Hinman, M.R., \& Paloski, W.H. (2007). Vibration exposure and biodynamic responses during whole-body vibration training. Medicine and Science in Sports and Exercise, 39, 1794-1800.

Bazett-Jones, D.M., Finch, W.H., \& Dugan, E.L. (2008). Comparing the effects of various whole-body vibration accelerations on counter-movement jump performance. Journal of Sports, Science, and Medicine, 7(1), 144-150.

BeDell, K.K., Scremin, A.M.E., Perell, K.L., \& Kunkel, C.F. (1996). Effects of functional electrical stimulation-induced lower extremity cycling on bone density of spinal cordinjured patients. American Journal of Physical Medicine \& Rehabilitation, 75(1), 29-34.

Bogaerts, A., Delecluse, C., Claessens, A.L., Coudyzer, W., Boonen, S., \& Verschueren, S.M. (2007). Impact of whole-body vibration training versus fitness training on muscle strength and muscle mass in older men: a 1-year randomized controlled trial. The Journals of Gerontology. Series A, Biological Sciences and Medical Sciences, 62(6), 630-635.

Chen, S.C., Lai, C.H., Chan, W.P., Huang, M.H., Tsai, H.W., \& Chen, J.J. (2005). Increases in bone mineral density after functional electrical stimulation cycling exercises in spinal cord injured patients. Disability and Rehabilitation, 27, 1337-1341.

Delecluse, C., Roelants, M., \& Verschueren, S. (2003). Strength increase after whole-body vibration compared with resistance training. / augmentation de la force suite a une vibration du corps entier comparee a un entrainement de musculation. Medicine and Science in Sports and Exercise, 35, 1033-1041.

Dolny, D., \& Reyes, F. (2008). Whole body vibration exercise: Training and benefits. Current Sports Medicine Reports, 7(3), 152-157.

Eng, J.J., Levins, S.M., Townson, A.F., Mah-Jones, D., Bremner, J., \& Huston, G. (2001). Use of prolonged standing for individuals with spinal cord injuries. Physical Therapy, $81,1392-1399$.

Flieger, J., Karachalios, T., Khaldi, L., Raptou, P., \& Lyritis, G. (1998). Mechanical stimulation in the form of vibration prevents postenopausal bone loss in ovariectomized rats. Calcified Tissue International, 63, 510-514.

Garatachea, N., Jimenez, A., Bresciani, G., Marino, N.A., Gonzalez-Gallego, J., \& De Paz, J.A. (2007). The effects of movement velocity during squatting on energy expenditure and substrate utilization in whole-body vibration. Journal of Strength and Conditioning Research, 21, 594-598.

Giangregorio, L., \& Blimkie, C.J.R. (2002). Skeletal adaptations to alterations in weightbearing activity: A comparison of models of disuse osteoporosis. Sports Medicine (Auckland, N.Z.), 32, 459-476.

Giangregorio, L., \& McCartney, N. (2006). Bone loss and muscle atrophy in spinal cord injury: Epidemiology, fracture prediction, and rehabilitation strategies. The Journal of Spinal Cord Medicine, 29, 489-500.

Giangregorio, L.M., Webber, C.E., Phillips, S.M., Hicks, A.L., Craven, B.C., Bugaresti, J.M., et al. (2006). Can body weight supported treadmill training increase bone mass and reverse muscle atrophy in individuals with chronic incomplete spinal cord injury? Applied Physiology, Nutrition, and Metabolism, 31, 283-291.

International Society for Clinical Densitometry. Available at: http://www.iscd.org. Retrieved March 2008.

Jacobs, P.L., \& Beekhuizen, K.S. (2005). Appraisal of physiological fitness in persons with spinal cord injury. Topics in Spinal Cord Injury Rehabilitation, 10(4), 32-50.

Jiang, S.D., Dai, L.Y., \& Jiang, L.S. (2006). Osteoporosis after spinal cord injury. Osteoporosis International, 17, 180-192. 
Jones, L.M., Legge, M., \& Goulding, A. (2002). Intensive exercise may preserve bone mass of the upper limbs in spinal cord injured males but does not retard demineralization of the lower body. Spinal Cord, 40(5), 230-235.

Jordan, M.J., Norris, S.R., Smith, D.J., \& Herzog, W. (2005). Vibration training: An overview of the area, training consequences, and future considerations. Journal of Strength and Conditioning Research, 19, 459-466.

Kiratli, B.J. (2003). Bone loss and osteoporosis following spinal cord injury. In V. Lin \& D. Cardenas (Eds.), Spinal Cord Medicine (pp. 539-548). New York: Demos Medical Publishing.

Kiratli, B.J., Smith, A.E., Nauenberg, T., Kallfelz, C.F., \& Perkash, I. (2000). Bone mineral and geometric changes through the femur with immobilization due to spinal cord injury. Journal of Rehabilitation Research and Development, 37, 225-233.

Kocina, P. (1997). Body composition of spinal cord injured adults. Sports Medicine (Auckland, N.Z.), 23, 48-60.

Lazo, M.G., Shirazi, P., Sam, M., Giobbie-Hurder, A., Blacconiere, M.J., \& Muppidi, M. (2001). Osteoporosis and risk of fracture in men with spinal cord injury. Spinal Cord, 39(4), 208-214.

Leeds, E.M., Klose, K.J., Ganz, W., Serafini, A., \& Green, B.A. (1990). Bone mineral density after bicycle ergometry training. Archives of Physical Medicine and Rehabilitation, 71, 207-209.

Lockette, K., \& Keyes, A. (1994). Conditioning with physical disabilities. Champaign, IL: Human Kinetics.

Maïmoun, L., Fattal, C., Micallef, J., Peruchon, E., \& Rabischong, P. (2006). Bone loss in spinal cord-injured patients: From physiopathology to therapy. Spinal Cord, 44(4), 203-210.

Moran, K., McNamara, B., \& Luo, J. (2007). Effect of vibration training in maximal effort (70\% 1RM) dynamic bicep curls. Medicine and Science in Sports and Exercise, 39, $526-533$.

Needham-Shropshire, B.M., Broton, J.G., Klose, K.J., Lebwohl, N., Guest, R.S., \& Jacobs, P.L. (1997). Evaluation of a training program for persons with SCI paraplegia using the parastep 1 ambulation system: Part 3. lack of effect on bone mineral density. Archives of Physical Medicine and Rehabilitation, 78, 799-803.

Poole, K.E.S., Warburton, E.A., \& Reeve, J. (2005). Rapid long-term bone loss following stroke in a man with osteoporosis and atherosclerosis. Osteoporosis International, 16, 302-305.

Portney, L., \& Watkins, M. (2009). Foundations of clinical research: Applications to practice (2nd ed.). Upper Saddle River, NJ: Prentice Hall.

Rimmer, J. (1994). Fitness and rehabilitation programs for special populations. Madison, WI: Brown and Benchmark.

Roelants, M., Delecluse, C., Goris, M., \& Verschueren, S. (2004). Effects of 24 weeks of whole body vibration training on body composition and muscle strength in untrained females. International Journal of Sports Medicine, 25(1), 1-5.

Rubin, C., Recker, R., Cullen, D., Ryaby, J., McCabe, J., \& McLeod, K. (2004). Prevention of postmenopausal bone loss by a low-magnitude, high-frequency mechanical stimulus: A clinical trial assessing compliance, efficacy, and safety. Journal of Bone and Mineral Research, 19, 343-351.

Semerjian, T.Z., Montague, S.M., Dominguez, J.F., Davidian, A.M., \& de Leon, R.D. (2005). Enhancement of quality of life and body satisfaction through the use of adapted exercise devices for individuals with spinal cord injuries. Topics in Spinal Cord Injury Rehabilitation, 11(2), 95-108. 
Verschueren, S.M., Roelants, M., Delecluse, C., Swinnen, S., Vanderschueren, D., \& Boonen, S. (2004). Effects of 6-month whole body vibration training on hip density, muscle strength, and postural control in postmenopausal women: A randomized controlled pilot study. Journal of Bone and Mineral Research, 19, 352-359.

Walter, J.S., Sola, P.G., Sacks, J., Lucero, Y., Langbein, E., \& Weaver, F. (1999). Indications for a home standing program for individuals with spinal cord injury. The Journal of Spinal Cord Medicine, 22(3), 152-158.

Ward, K., Alsop, C., Caulton, J., Rubin, C., Adams, J., \& Mughal, Z. (2004). Low magnitude mechanical loading is osteogenic in children with disabling conditions. Journal of Bone and Mineral Research, 19, 360-369.

Weiss, D. (2003). Osteoporosis and spinal cord injury. Emedicine. Available at: http:// emedicine.medscape.com/article/322204-overview. Retrieved March 25, 2009. 
Copyright of Adapted Physical Activity Quarterly is the property of Human Kinetics Publishers, Inc. and its content may not be copied or emailed to multiple sites or posted to a listserv without the copyright holder's express written permission. However, users may print, download, or email articles for individual use. 